\title{
Comparison between Ormeloxifene and Norethisterone in reducing menorrhagia in dysfunctional uterine bleeding
}

\author{
Swati Gett*, Shruti Singh
}

Department of Obstetrics and Gynecology, Kasturba Hospital, Delhi, India

Received: 19 September 2018

Accepted: 22 October 2018

*Correspondence:

Dr. Swati Gett,

E-mail: swatigett@gmail.com

Copyright: (C) the author(s), publisher and licensee Medip Academy. This is an open-access article distributed under the terms of the Creative Commons Attribution Non-Commercial License, which permits unrestricted non-commercial use, distribution, and reproduction in any medium, provided the original work is properly cited.

\begin{abstract}
Background: Dysfunctional Uterine Bleeding (DUB) is a condition that affects nearly every woman at some point in her life. This study aims to compare the efficacy of Ormeloxifene and Norethisterone in reducing menorrhagia in such patients.

Methods: This prospective study was done on 100 women presenting with dysfunctional uterine bleeding, of 20-50 years of age, who were ready for follow-up and were allocated into two equal groups, one was given Ormeloxifene and the other was given Norethisterone for a period of 3 months. Haemoglobin levels, endometrial thickness on ultrasound and Pictorial Blood loss Assessment Chart (PBAC) scores were assessed before and after the treatment.

Results: It was found that both Ormeloxifene and Norethisterone reduced menorrhagia, with a significant difference in PBAC scores ( $p$ value $<0.05$ ). There was a notable reduction in PBAC scores in Ormeloxifene group $(66.53 \%$ change from pretreatment mean value) as compared to Norethisterone group (31.38\% change from pretreatment mean value); and same holds true for the change in haemoglobin levels as well as endometrial thickness. Ormeloxifene was found to have a greater effect on heavy menstrual bleeding in comparison to Norethisterone.

Conclusions: Ormeloxifene is a new modality and is found to be a better option in reducing menorrhagia in DUB in respect to a greater success rate, better compliance and cost effectiveness.
\end{abstract}

Keywords: Endometrial thickness, Dysfunctional uterine bleeding, Norethisterone, Ormeloxifene, PBAC score

\section{INTRODUCTION}

Dysfunctional Uterine Bleeding (DUB) is defined as a state of abnormal uterine bleeding without any clinically detectable organic pelvic pathology like tumor, inflammation or pregnancy and is a diagnosis of exclusion.

It is the most common cause of abnormal vaginal bleeding during a woman's reproductive years. ${ }^{1}$

The treatment options for dysfunctional uterine bleeding are diverse, which can be finally tailored to cater the needs of patients of different socioeconomic background, different age groups and different reproductive needs. ${ }^{2}$
Treatment options range from offering medical measures such as cyclooxygenase inhibitors, tranexamic acid, hormonal agents and in cases not managed by medical therapy offering surgical management. ${ }^{3}$

Ormeloxifene (also known as Centchroman) is one of the selective estrogen receptor modulators. It is a nonsteroidal, non-hormonal oral contraceptive which is taken once a week. ${ }^{4}$ In India, Ormeloxifene has been available as a birth control product since the early 1990s.

It is developed as Centchroman by Indian Central Drug Research Institute, Lucknow, India and it is currently marketed here under the trade name, Saheli. ${ }^{5}$ It mediates its effects by high affinity interaction with estrogen 
receptors, antagonizing the effect of estrogen on uterine and breast tissue and stimulating effect on vagina, bone, cardiovascular system and central nervous system. ${ }^{6}$ Norethisterone (a conventional progesterone) is the most frequently prescribed drug for dysfunctional uterine bleeding serving $38 \%$ of the patient population, the reason being cost effectiveness and absence of side effects.

It suppresses endometrial development, re-establish predictable bleeding patterns, decrease menstrual flow and lower the risk of iron deficiency anaemia. ${ }^{7}$

\section{METHODS}

In the present study, patients presenting with dysfunctional uterine bleeding (DUB) to the Department of Obstetrics and Gynaecology, Sardar Patel Medical College, Bikaner, Rajasthan (India) during the specified period from September 2015 to August 2016 were taken up for study.

This was a comparative prospective study conducted in which 100 women between 20-50 years presenting with abnormal uterine bleeding without any organic, systemic or iatrogenic cause were enrolled.

\section{Inclusion criteria}

- All patients with DUB of 20-50 years of age were included in the study.

- All patients who were ready for follow up.

\section{Exclusion criteria}

- Patients who were pregnant, lactating, with history of heart disease, hypertension, migraine, polycystic ovarian disease, liver and kidney impairment and thyroid dysfunction were excluded.

- Also, patients with fibroid uterus, adenomyosis, atypical endometrial hyperplasia, bleeding disorders were also excluded.

Informed consent was taken from all the patients. After obtaining an approval from institutional ethics committee, a detailed history and clinical examination was done.

As DUB is a diagnosis of exclusion, investigations were done to rule out any other possible cause for abnormal uterine bleeding. These included complete blood cell count including haemoglobin $(\mathrm{Hb})$ level, thyroid stimulating hormone, coagulation profile, PAP smear, pelvic ultrasound to measure endometrial thickness and rule out any pelvic pathology and endometrial sampling.

The cases were advised to maintain a menstrual diary to record the total number of days of bleeding, number of sanitary pads used, degree of soaking of each pad, number and size of clots passed, and if dysmenorrhoea experienced.

The Pictorial Blood loss Assessment Chart (PBAC) Scoring was then done accordingly to assess menstrual blood loss. PBAC is a simple procedure for objective assessment of menstrual blood loss. A PBAC score $\geq 100$ indicates a menstrual blood loss $\geq 80 \mathrm{ml}$ and is considered diagnostic for menorrhagia. ${ }^{8}$

The women were allocated into 2 groups, and cases were taken until each group had 50 cases, who were ready for follow-up. Group A was given Ormeloxifene tablet 60 mg twice a week for 12 weeks and group B was given Norethisterone tablet $5 \mathrm{mg}$ twice a day for 21 days followed by 7 days withdrawal, for 3 months. Patients were followed up at 3 months.

During each visit a detailed menstrual history was taken, PBAC score was calculated. Haemoglobin level and endometrial thickness were measured after 3 months of the treatment. Any side effects, if experienced, were also noted.

The primary outcome measures were reduction in amount of menstrual blood loss which was assessed by fall in PBAC score, rise in hemoglobin level and reduction in endometrial thickness done in proliferative phase by an ultrasound.

All outcome measuring parameters were presented as Mean and were analyzed using the $\mathrm{Z}$ technique. Statistical significance was taken as $\mathrm{p} \leq 0.05$.

\section{RESULTS}

Table 1 shows analysis of age distribution. $50 \%$ of cases in Group A and $48 \%$ in Group B belonged to age group between 31-40 years, with mean age of 37.90 years in Group A and 35.40 years in Group B. The two groups were comparable to each other.

Majority (94\%) of the patients were multiparae. In Group A, $46 \%$ of patients had 4 or more children and in Group $\mathrm{B}, 32 \%$ had 3 and $32 \%$ had 2 children.

Both the groups were comparable to each other. Most of the patients belonged to rural population, with $56 \%$ in Group A and 62\% in Group B.

With regard to distribution of patients according to duration of symptoms, most of the patients had 4-6 months of duration of symptoms (34\% in Group A and $36 \%$ in Group B). Mean duration of symptoms in Group A was 6.8 months and in Group B was 6.7 months. Mean haemoglobin level in Group A was $7.3 \mathrm{gm} \%$ and in Group B was $7.5 \mathrm{gm} \%$. Most of the patients had endometrial thickness in the range of 10.1 to $15 \mathrm{~mm}$ (64\% in Group A and $76 \%$ in group B). 
Table 1: Distribution of variables among study subjects.

\begin{tabular}{|c|c|c|c|c|}
\hline \multirow{2}{*}{ Variables } & \multicolumn{2}{|c|}{ Drug A group (Ormeloxifene) } & \multicolumn{2}{|c|}{ Drug B group (Norethiesterone) } \\
\hline & No. & $\%$ & No. & $\%$ \\
\hline \multicolumn{5}{|c|}{ Distribution of patients according to age (in years) } \\
\hline $20-30$ & 9 & 18 & 17 & 34 \\
\hline $31-40$ & 25 & 50 & 24 & 48 \\
\hline $41-50$ & 16 & 32 & 9 & 18 \\
\hline Total & 50 & 100 & 50 & 100 \\
\hline \multicolumn{5}{|c|}{ Distribution of patients according to parity } \\
\hline 1 & 1 & 2 & 5 & 10 \\
\hline 2 & 12 & 24 & 16 & 32 \\
\hline 3 & 14 & 28 & 16 & 32 \\
\hline$>=4$ & 23 & 46 & 13 & 26 \\
\hline Total & 50 & 100 & 50 & 100 \\
\hline \multicolumn{5}{|c|}{ Distribution of patients according to residence } \\
\hline Urban & 22 & 44 & 19 & 38 \\
\hline Rural & 28 & 56 & 31 & 62 \\
\hline Total & 50 & 100 & 50 & 100 \\
\hline \multicolumn{5}{|c|}{ Distribution of patients according to duration of symptoms (in months) } \\
\hline $0-3$ & 11 & 22 & 10 & 20 \\
\hline 4-6 & 17 & 34 & 18 & 36 \\
\hline $7-9$ & 12 & 24 & 11 & 22 \\
\hline $10-12$ & 9 & 18 & 10 & 20 \\
\hline$>12$ & 1 & 2 & 1 & 2 \\
\hline Total & 50 & 100 & 50 & 100 \\
\hline \multicolumn{5}{|c|}{ Hemoglobin (gm\%) level of patients prior to treatment } \\
\hline$<6$ & 3 & 6 & 2 & 4 \\
\hline $6-8$ & 36 & 72 & 35 & 70 \\
\hline $8.1-10$ & 11 & 22 & 13 & 26 \\
\hline Total & 50 & 100 & 50 & 100 \\
\hline \multicolumn{5}{|c|}{ Endometrial thickness $(\mathrm{mm})$ on USG prior to treatment } \\
\hline $0-5$ & 1 & 2 & 0 & 0 \\
\hline $5.1-10$ & 12 & 24 & 10 & 20 \\
\hline $10.1-15$ & 32 & 64 & 38 & 76 \\
\hline $15.1-20$ & 5 & 10 & 2 & 4 \\
\hline Total & 50 & 100 & 50 & 100 \\
\hline \multicolumn{5}{|c|}{ PBAC score prior to treatment } \\
\hline $100-200$ & 3 & 6 & 0 & 0 \\
\hline $201-300$ & 33 & 66 & 39 & 78 \\
\hline $301-400$ & 14 & 28 & 11 & 22 \\
\hline Total & 50 & 100 & 50 & 100 \\
\hline
\end{tabular}

Table 2: Mean of baseline characteristics of patients.

\begin{tabular}{|llll|}
\hline Baseline characteristics & Drug A (Ormeloxifene) & Drug B (Norethisterone) & p-value \\
\hline Age (years) & Mean & Mean & - \\
\hline Parity & 37.90 & 35.40 & - \\
\hline Duration of symptoms (months) & 3.40 & 2.80 & 0.872 \\
\hline Haemoglobin (gm\%) & 6.86 & 6.76 & 0.397 \\
\hline Endometrial thickness (mm) & 7.30 & 7.5 & 0.709 \\
\hline PBAC score & 11.9 & 11.7 & 0.942 \\
\hline
\end{tabular}

Mean PBAC score in both the groups was 274 with most of the patients in the range of 201-300 (66\% in Group A and $78 \%$ in group B) (Table 2). Table 3 shows the comparison in between Drug A and Drug B in respect to 
pre- and post-treatment values of mean PBAC score, mean haemoglobin concentration and mean endometrial thickness, and all these were found to be significant in both the groups ( $\mathrm{p}$ value $<0.05$ ).

Table 3: Comparison between pre- and post-treatment values of different parameters.

\begin{tabular}{|llll}
\hline Group & Pre-treatment & After 3 months of treatment & p-value \\
\hline Mean PBAC score & & & 01.7 \\
\hline Drug A group (Ormeloxifene) & 274 & 188 & 0.0004 \\
\hline Drug B group (Norethisterone) & 274 & & 0.0009 \\
\hline Mean Hb (gm\%) & & 9.6 & 0.0006 \\
\hline Drug A group (Ormeloxifene) & 7.3 & 8.5 & 0.0008 \\
\hline Drug B group (Norethisterone) & 7.5 & & 0.0003 \\
\hline Mean endometrial thickness (mm) & & 7.9 & 0.0006 \\
\hline Drug A group (Ormeloxifene) & 11.9 & 10.3 & \\
\hline Drug B group (Norethisterone) & 11.7 & & \\
\hline
\end{tabular}

It also shows change in PBAC score after 3 months of treatment, with percentage change of $66.53 \%$ in Group A and $31.38 \%$ in Group B.

The percentage change in haemoglobin was of $31.5 \%$ in Group A and of $13.3 \%$ in Group B; and the percentage change in endometrial thickness of $25.2 \%$ in Group A and of $11.9 \%$ in Group B, which was all significant (p value $<0.05)$.

Table (04) shows the side effects of the given treatment, which were mild, and they didn't affect the compliance of the patients receiving the treatment.

Table 4: Side effects of treatment.

\begin{tabular}{|lllll|}
\hline Side effects & \multicolumn{2}{l|}{$\begin{array}{l}\text { Drug A group } \\
\text { (Ormeloxifene) }\end{array}$} & \multicolumn{2}{l|}{$\begin{array}{l}\text { Drug B group } \\
\text { (Norethisterone) }\end{array}$} \\
\cline { 2 - 4 } & No. & $\%$ & No. & $\%$ \\
\hline Nausea & 7 & 14 & 10 & 20 \\
\hline Headache & 3 & 6 & 3 & 6 \\
\hline White discharg & 6 & 12 & 2 & 4 \\
\hline Spotting & - & - & 5 & 10 \\
\hline Total & 13 & 26 & 16 & 32 \\
\hline p-value & 0.972 & & & \\
\hline
\end{tabular}

Most common side effect in both the groups was nausea. $26 \%$ of patients in Group A had side effects out of which $14 \%$ had nausea and in Group B, 32\% patients had side effects out of which $20 \%$ had nausea.

Side effects are slightly more in Group B, but the $\mathrm{p}$ value was not significant. Table (05) shows the comparison of both the drugs by their market price.

The cost of one tablet of ormeloxifene is Rs.9 and that of norethisterone is Rs.4, so the total cost of 3 months of treatment with Drug A would be Rs.216 and that with Drug B would be Rs.504, which is almost twice that of
Drug A, thereby making Drug A more cost effective in comparison to Drug B.

Table 5: Comparison of both drugs by market price.

\begin{tabular}{|lll|}
$\begin{array}{lll}\text { Market price } \\
\text { (in Rupees) }\end{array}$ & $\begin{array}{l}\text { Drug A } \\
\text { (Ormeloxifene) }\end{array}$ & $\begin{array}{l}\text { Drug B } \\
\text { (Norethisterone) }\end{array}$ \\
\hline $\begin{array}{l}\text { Cost of one tablet } \\
\text { Cost of drug for 3 } \\
\text { months of treatment }\end{array}$ & 216 & 4 \\
\hline
\end{tabular}

\section{DISCUSSION}

Dysfunctional uterine bleeding (DUB) is a common problem seen in women of reproductive age group.

The mean age of the patients was 37.90 years in Group A and 35.40 years in Group B. This study group is also comparable with previous studies. ${ }^{9-11}$

The reason could be that in younger years of the reproductive life, the heavy menstrual bleeding might not cause much of a trouble to the affected women as most of the times the bleeding is temporarily halted during the pregnancies and the health status of young women is mostly better than the women in their later years of life, so they usually present late to the hospital.

Most of the patients were multiparae, which was also comparable to the previous studies. ${ }^{9-11}$

The duration of symptoms was high as seen in previous studies also, the reason could be that these women are usually neglected, so they present late to the hospital. ${ }^{9,11}$

There was decrement in PBAC score in both the groups after 3 months of treatment, with percentage change in PBAC score of $66.53 \%$ in Group A and of $31.38 \%$ in Group B (Figure 01). 


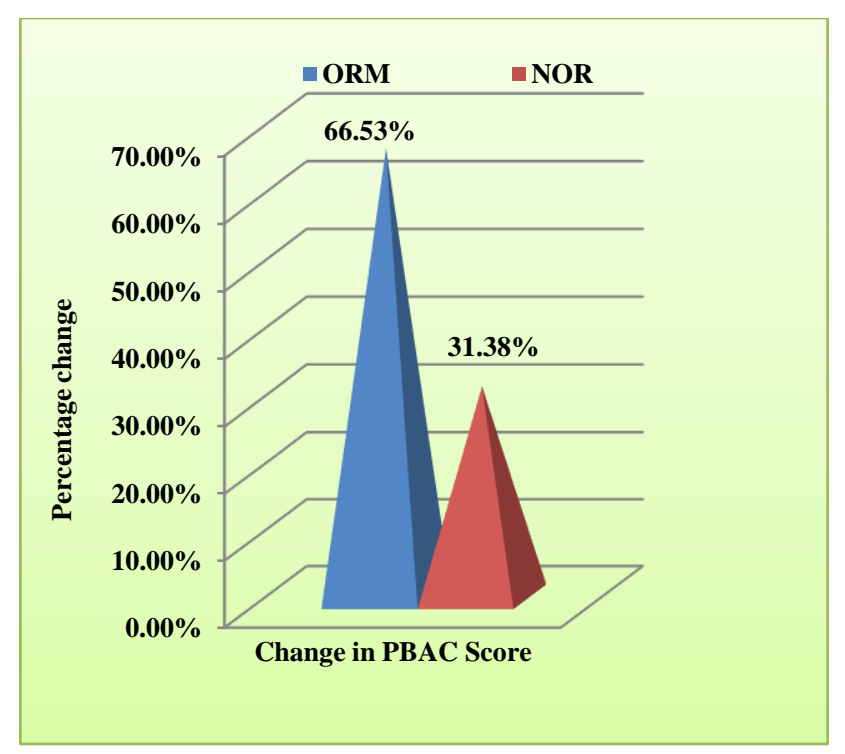

Figure 1: Percentage change in PBAC score after treatment.

The haemoglobin levels increased significantly in these patients after 3 months of treatment, with percentage change in haemoglobin of $31.5 \%$ in Group A and of $13.3 \%$ in Group B (Figure 02).

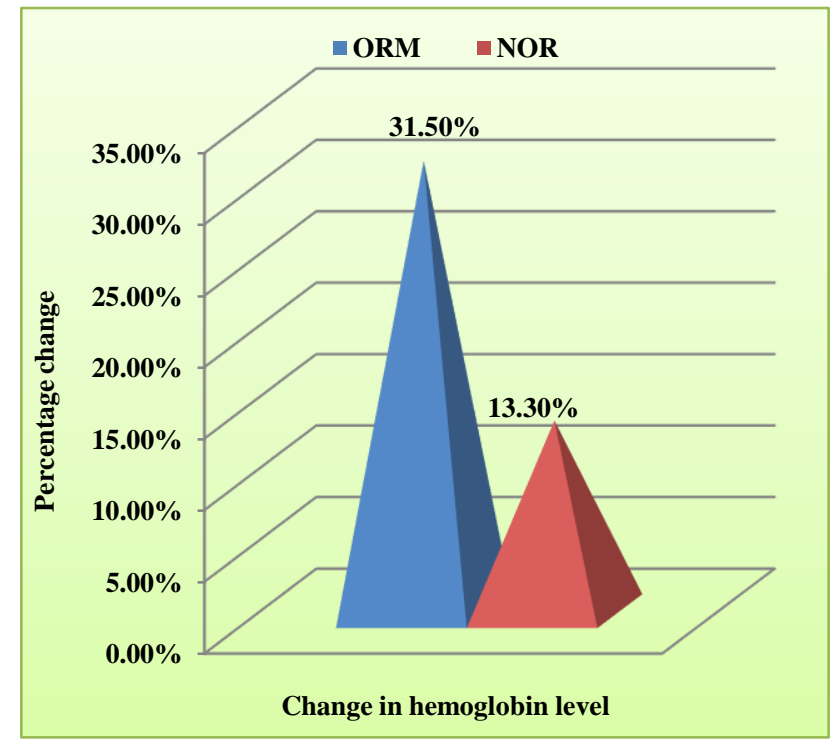

Figure 2: Percentage change in haemoglobin levels after treatment.

The endometrial thickness on ultrasonography decreased after 3 months of treatment, with percentage change in thickness of $25.2 \%$ in Group A and of $11.9 \%$ in Group B (Figure 03). All of which was significant ( $p$ value $<0.05$ ) and similar to previously conducted studies. ${ }^{9,10,12,13}$ This shows a decrement in the amount of menstrual blood loss over the course of treatment. PBAC score is not routinely used to assess the menstrual blood loss in patients attending the hospitals, but it should be considered for this purpose. As seen in present study, PBAC score directly correlates to the haemoglobin levels in patients where the cause of anaemia was only heavy menstrual blood loss. PBAC score can help in subjective quantification of blood loss during each cycle and can be used as a helpful guide in patients requiring some kind of intervention, even before the development of anaemia and before any significant effect on their quality of life.

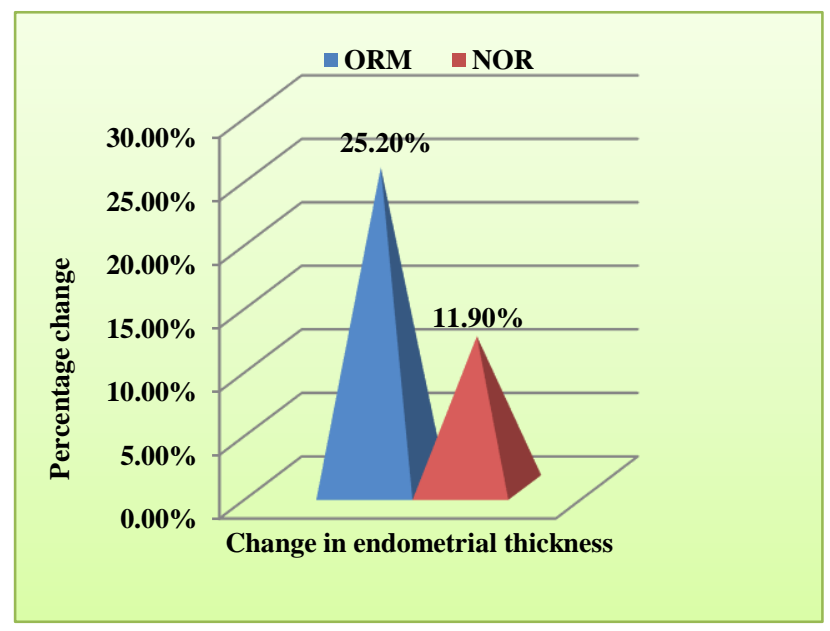

Figure 3: Percentage change in endometrial thickness after treatment.

The PBAC scores, if mentioned, in previous records can be very helpful for comparison and quantification of blood loss. There were few minor side effects in both the treatment groups which did not cause any failure of compliance. Ormeloxifene is more cost effective in comparison to conventional progesterone. On comparison with Norethisterone (a conventional progesterone), in present study, we found Ormeloxifene to be a better option in respect to a greater success rate, better compliance and cost effectiveness.

\section{CONCLUSION}

Dysfunctional Uterine Bleeding (DUB) is considered to be caused because of the hormonal imbalance, eventually leading to hyperestrogenic state, which can be quite successfully treated by the medical management, like conventional progestins or Selective Estrogen Receptor Modulators.

The ideal therapy to treat DUB should be a designer drug which can block the action of estrogen on the endometrium, but not its beneficial actions in the body.

PBAC score is a simple tool for assessment of menstrual blood loss. It is quite cost effective as it requires no special equipment's or setup and is less time consuming also. With this score, we can easily differentiate women having normal blood flow during menses from those having heavy menstrual bleeding. It can be helpful in quantifying, comparing and documenting the amount of bleeding during each cycle, and also to see the efficacy of the treatment in patients of abnormal uterine bleeding. 
So, this score should be routinely used in patients complaining of heavy menstrual bleeding.

However, present study is on a small scale and is of short duration and larger multicentric studies and trials are required to recommend Ormeloxifene as an ideal regime for the treatment of dysfunctional uterine bleeding.

Funding: No funding sources

Conflict of interest: None declared

Ethical approval: The study was approved by the Institutional Ethics Committee

\section{REFERENCES}

1. Doshi HU, Kriplani A. Clinical cases in Obstetrics and Gynaecology, $1^{\text {st }}$ ed. 2003; 250-251.

2. Coulter A, Kelland J, Peto V, Rees MC. Treating menorrhagia in primary care: an overview of drug trials and a survey of prescribing practice. Int $\mathbf{J}$ Technol Ass Health Care. 1995;11(3):456-71.

3. Lethaby A, Farquhar C, Cooke I. Antifibrinolytics for heavy menstrual bleeding. Cochrane Database Syst Rev. 2000;(4):CD000249.

4. V.L. Bhargava. Textbook of Gynaecology ANE Books. 2nd ed 2009;109.

5. Bouchard P. Current and future medical treatments for menometrorrhagia during the premenopause. Gynecol Endocrinol. 2011; 27(1):1120-5.

6. Shelly W, Draper MW, Krishnan V, Wong M, Jaffe RB. Selective estrogen receptor modulators: an update on recent clinical findings. Obstet Gynecol Surv. 2008;63(3):163-81.

7. Samuel NC, Clark TJ. Future research into abnormal uterine bleeding. Best Pract Res Clin Obstet Gynaecol. 2007;21(6):1023-40.
8. National Collaborating Centre for Women's and Children's Health. Heavy menstrual bleeding 2013 Available https://www.nice.org.uk/guidance/cg132/evidence/fu ll-guideline-pdf-184810861

9. Mandal D, Parmanik S, Surana S, Hazra A, Mandal S, Maity TK. Comparative study of low-dose oral contraceptive pill and ormeloxifene in the treatment of dysfunctional uterine bleeding. Int J Health Allied Sci. 20143(4);225-31.

10. Deepika Dhananjayan and Mirunalini et al. Comparative study between ormeloxifene and norethisterone in the improvement of menstrual blood loss (mbl) in abnormal uterine bleeding Int $\mathbf{J}$ Current Med Pharmaceut Res. 2016:2;(10):758-61

11. Agarwal N, Singh S, Singh S, Agarwal M, Manocha P. Comparative evaluation of the efficacy and safety of ormeloxifene and norethisterone in dysfunctional uterine bleeding Int J Reprod Contracept Obstet Gynecol. 2013;2(2);194-8.

12. Shahab F, Jain S, Jain J, Jain U. Ormeloxifene: Boon to perimenopausal Dysfunctional Uterine Bleeding (DUB) women in avoiding hysterectomies. Int J Med Sci Educat.2014;1(1):21-9.

13. Kriplani A, Kulshrestha V, Agarwal N. Efficacy and safety of ormiloxefene hcl in management of menorrhagia, A pilot study. J Obst and Gynecol, 2009;35(4):746-52.

Cite this article as: Gett $\mathrm{S}$, Singh $\mathrm{S}$. Comparison between Ormeloxifene and Norethisterone in reducing menorrhagia in dysfunctional uterine bleeding. Int J Reprod Contracept Obstet Gynecol 2018;7:4966-71. 